\title{
Preparation of modified $\mathrm{ZnO}$ nanoparticles for photocatalytic degradation of chlorobenzene
}

\author{
Pallavi Nagaraju $^{1} \cdot$ Shivaraju Harikaranahalli Puttaiah ${ }^{1,2} \oplus \cdot$ Kitirote Wantala $^{3} \cdot$ Behzad Shahmoradi $^{2,4}$
}

Received: 24 March 2020 / Accepted: 6 May 2020 / Published online: 18 May 2020

(c) The Author(s) 2020

\begin{abstract}
Volatile organic compounds (VOCs) are one of the major pollutants present in the petrochemical industrial effluents. These VOCs have high vapor pressure, which makes it to be dispersed into the atmosphere easily. Chlorobenzene is one such VOC, which has an ability to cause adverse impacts on human health by damaging the central nervous systems. The available treatment methods are unable to effectively treat such VOCs in environment. Photocatalytic degradation is the effective and economical methods, which are being used for the treatment of such pollutants. $\mathrm{ZnO}$ is one of the widely accepted photocatalyst, but it has a limitation of wide band-gap energy utilization. This paper mainly investigates the preparation of metal-doped $\mathrm{ZnO}$ nanoparticles using solgel technique and its application for the degradation of chlorobenzene in an aqueous media under different light sources. Among the modified $\mathrm{ZnO}$ nanoparticles prepared $(\mathrm{Ag} / \mathrm{ZnO}, \mathrm{Cd} / \mathrm{ZnO}$ and $\mathrm{Pb} / \mathrm{ZnO})$, $\mathrm{Pb} / \mathrm{ZnO}$ was found to be very effective in the degradation of chlorobenzene and achieved up to $100 \%$ within a short duration $(<120 \mathrm{~min})$. The $\mathrm{Pb} / \mathrm{ZnO}$ was also used as a photocatalyst in a vertical continuous photoreactor for the photodegradation of chlorobenzene using LED light.
\end{abstract}

Keywords Volatile organic compound $\cdot$ Chlorobenzene $\cdot$ Nanoparticles $\cdot$ Photocatalysis, modified ZnO

\section{Introduction}

Volatile organic compounds (VOCs) are the organic compounds, which have high vapor pressure at room temperature, and they are characterized by low water solubility (Goldstein Allen 2007; Guo et al. 2009). Rapid industrialization and urbanization have led to serious environmental pollution problems that impact on the human health at global level. VOCs play a critical role in photochemical reactions, which give rise to highly toxic secondary and intermediate

Shivaraju Harikaranahalli Puttaiah

shivarajuenvi@gmail.com

1 Department of Water and Health, JSS Academy of Higher Education and Research, Mysuru 570015, India

2 Center for Water, Food and Energy, GREENS Trust, Harikaranahalli Village, Dombaranahalli Post, Turuvekere Taluka, Tumkur District, Karnataka 572215, India

3 Department of Chemical Engineering, Faculty of Engineering, Khon Kaen University, Khon Kaen, Thailand

4 Department of Environmental Health Engineering, Environmental Health Research Center, Kurdistan University of Medical Sciences, Sanandaj, Iran pollutants. However, severe impacts of VOCs which are disposed by anthropogenic activities, on the human health and environment from the past few years, have been realized (Tanizaki et al. 2007). Recently, evidences are rapidly growing to show the potential health hazards associated with VOCs and their involvement with global climate change and few VOCs species were shown to be highly toxic, mutagenic and carcinogenic (Said Ismail and Hameed 2013). Apart from potential health impacts of VOCs, they are also involved in photochemical reactions leading to the formation of oxidants, which have serious deleterious effects on human health, agricultural crops, trees, natural vegetation, buildings, materials, etc. (Lin et al. 2013; Prabhat Kumar et al. 2011; Zou et al. 2006). Chlorobenzene is a colorless and flammable aromatic compound with molecular formula $\mathrm{C}_{6} \mathrm{H}_{5} \mathrm{Cl}$. Chlorobenzene is primarily used as a solvent, a degreasing agent and as a chemical intermediate in various industries. Chlorobenzene causes various health effects like skin irritation, skin and eyes allergies, nose and throat rashes, and exposure to very high concentration can cause headache, dizziness. Acute inhalation causes narcosis, restlessness, tremors and muscle spasms. Chronic (long-term) exposure of humans to chlorobenzene affects the central 
nervous system (CNS). They can damage the lung, liver and kidney by inhalation. Signs of neurotoxicity in humans include numbness, cyanosis, hyperesthesia (increased sensation) and muscle spasms. EPA has classified chlorobenzene as a Group D, not classifiable as to human carcinogenicity. There are various technologies, which have been currently used for the treatment or elimination of VOCs. Physicochemical and biological treatment methods are available for the removal of VOCs by recovery method or destruction method (Berenjian et al. 2012; Das et al. 2004; Font et al. 2011; Huang et al. 2016; Prabhat Kumar et al. 2011; Reddy et al. 2011). Biological treatment techniques are designed on the capability of microorganisms to degrade the organic pollutants under aerobic conditions through oxidative and reductive reactions to water vapor, carbon dioxide, inorganic products and organic biomass. The biological techniques confide on two important fundamental mechanisms. Drawback with absorption technique generates wastewater which needs further treatment, high initial investment, difficult in design, start-up time constraints, requires a precise maintenance of the system, and is not suitable method for lower concentrations of VOCs (Khan and Kr. Ghoshal 2000; Prabhat Kumar et al. 2011). The traditional methods used for VOCs treatment such as adsorption on activated charcoal, biofiltration and normal treatment methods are challenged by many factors such as energy requirements, expenses for scaling up large-scale applications, inefficient to degrade most of these organic compounds, generation of toxic organic by-products, reusability problem, generation of waste and waste disposal problem (Eltouny 2009; Huang et al. 2016). Advanced oxidation process (AOP) is a process that associates the production of reactive oxidizing agent such as hydroxyl radicals in sufficient quantity for the degradation of complex organic compounds present in both water and wastewater. The preeminent objective of AOP is to completely degrade the toxic organic pollutants to non-detectable limits from the ppb or ppm range without generating hazardous secondary pollutants.

Photocatalysis can use a renewable energy source widely in the treatment of pollutants; thereby, it is environmental friendly and economic (Ameta et al. 2012). Photocatalysis using semiconductor has been enormously demonstrated for environmental applications as a cleanup process. Photocatalysis pathway is considered to be following a green chemistry due to its environmental friendly approach in degradation of various organic pollutants. Heterogeneous photocatalysis has been extensively used for the wastewater treatment and pollutant degradation into environmental friendly compounds. Research has been carried out to use zinc oxide $(\mathrm{ZnO})$ as a photocatalyst for the degradation of various hazardous industrial dyes and organic contaminants in water and wastewater. $\mathrm{ZnO}$ is one of the remarkable semiconductor-based photocatalytic material, and it has been widely used in various applications such as optical, electronics, optoelectronics, catalytic and lasers. The scope of the present research is to investigate the photocatalytic degradation of chlorobenzene using modified $\mathrm{ZnO}$ nanoparticles in a batch reactor under different light sources and to find an economical way to treat volatile organic compound.

\section{Material and methodology}

$\mathrm{ZnO}$ has great beneficial properties for photodegradation of various organic contaminants, visible light-based photocatalysis attributed to the wide band-gap energy $(3.37 \mathrm{eV})$ and large free-excitation binding energy $(60 \mathrm{meV})$ (Malik et al. 2013; Meena and Chouhan 2015; Rangkooy et al. 2012). Properties such as physicochemical stability, high thermal conductivity, high electron mobility, nontoxicity and large binding energy have make it as a novel semiconductor in the field of photocatalytic applications (Brintha and Ajitha 2015; Chen and Mao 2007; Hasnidawani et al. 2016; Khan et al. 2014). Nowadays, $\mathrm{TiO}_{2}$ has being widely used semiconductor in photocatalytic applications (Crutzen et al. 1999; Malekshahi Byranvand et al. 2013; Aneesh and Vanaja 2007; Rajput 2015; Salahuddin et al. 2015; Tseng et al. 2010; Wong et al. 2011) and modified $\mathrm{ZnO}$ can be an appropriate alternative semiconductor in photocatalytic applications, since it has showed a wider range of band-gap energy and photocatalytic activities significantly under visible range of photon sources (Ameta et al. 2012; Prieto et al. 2007; Zou et al. 2004). However, controlling the surface redox reactions and postponing the recombination of photoinduced electron-hole pairs and band-gap tuning are the major challenges that need to be addressed to enhance overall photocatalytic degradation efficiency of $\mathrm{ZnO}$ (Bacaksiz et al. 2008; Chen et al. 2003; Kim and Choi 2007; Sharma et al. 2014). The modification of $\mathrm{ZnO}$ semiconductor with noble metals and nonmetals has significantly attracted attention in semiconductor based heterogeneous photocatalysis (Anandan et al. 2010; Djurišić et al. 2014; Nakata and Fujishima 2012; Ramesh 2013; Rehman et al. 2009; Sharma et al. 2014). Recently, various metal and nonmetal ions such as $\mathrm{Ag}, \mathrm{Cd}, \mathrm{Fe}, \mathrm{Mn}, \mathrm{Co}, \mathrm{N}, \mathrm{Mg}$, and $\mathrm{Cu}$ have been used as doping ions to reduce the recombination of electron-hole pairs and reduce band-gap energy (Anandan et al. 2010; Djurišić et al. 2014; Nakata and Fujishima 2012; Ramesh 2013; Rehman et al. 2009; Sharma et al. 2014; Zaleskamedynska 2006).

\section{Preparation and characterization of modified $\mathrm{ZnO}$ nanoparticles}

Preparation of modified $\mathrm{ZnO}$ nanoparticles such as $\mathrm{Ag}$ doped $\mathrm{ZnO}(\mathrm{Ag} / \mathrm{ZnO})$, Cd-doped $\mathrm{ZnO}(\mathrm{Cd} / \mathrm{ZnO})$ and 
$\mathrm{Pb}$-doped $\mathrm{ZnO}(\mathrm{Pb} / \mathrm{ZnO})$ was carried out using solgel technique under alkaline conditions. Silver nitrite, cadmium sulfate and lead acetate were used as the dopant sources for the preparation of $\mathrm{Ag}(1 \%)-, \mathrm{Cd}(1 \%)$ - and $\mathrm{Pb}(1 \%)$-doped $\mathrm{ZnO}$ nanoparticles, respectively, with reagent grade $\mathrm{ZnO}$ powder as a core precursor of $\mathrm{ZnO}$. Standard solgel procedures were used for the preparation of modified $\mathrm{ZnO}$ nanoparticles (Midhun et al. 2017; Shivaraju 2012; Shivaraju and Byrappa 2012; Shivaraju and Chandrashekar 2012; Shivaraju et al. 2016). The obtained final products were dried at room temperature and calcinated at $500{ }^{\circ} \mathrm{C}$ for 2-h duration using preheated muffle furnace. As-prepared modified $\mathrm{ZnO}$ nanoparticles were characterized for band-gap energy using UV-Vis spectrophotometer (Shimazu UV-1800), powder X-ray diffraction (Bruker-Microstar Proteum 8), scanning electron microscopic images with energy-dispersive X-ray analysis (EVO LS 15, Carl Zeiss, Germany), Fourier transformed infrared spectroscopy (Shimadzu IRAffinity-1S), dynamic light scattering (Malvern Instruments Ltd.), BET surface area (Micromeritics TRIstar 3020, USA) and photocatalytic activities. The modified $\mathrm{ZnO}$ nanoparticles were used for the degradation of chlorobenzene of known concentration for duration of $5 \mathrm{~h}$ in a batch reactor. The initial and final concentration of chlorobenzene was determined using GC coupled with mass spectrometer (Shimadzu, Tokyo, Japan).

\section{Photocatalytic degradation of chlorobenzene using model vertical continuous photo reactor}

Based on the results obtained during photocatalytic degradation of chlorobenzene, a potential real-time application of semiconductor-based nanophotocatalyst in a laboratoryscale continuous reactor model was fabricated and demonstrated using aqueous solution. Designing of continuous photoreactor was carried out for vertical models by considering the flow rate, light illumination and catalyst loading mode. Reaction vessels made with quartz materials were used with less energy consuming photon sources such as light-emitting diodes (LEDs). Photocatalytic degradation of chlorobenzene was carried out using batch scale photoreactor of $50 \mathrm{~mL}$ capacity in a closed system under different light sources. Aqueous solution of about $20 \mu \mathrm{g} / \mathrm{L}$ of chlorobenzene was used for photocatalytic studies with $2 \mathrm{~h}$ irradiation time. About $25 \mathrm{mg}$ of each modified $\mathrm{ZnO}$ nanoparticles $(\mathrm{Ag} / \mathrm{ZnO}, \mathrm{Cd} / \mathrm{ZnO}$ and $\mathrm{Pb} / \mathrm{ZnO})$ was dispersed in aqueous solution of chlorobenzene and irradiated to different light sources (fluorescent light, UV light, tungsten light and LED light). Initial and final concentration of chlorobenzene in aqueous media was measured by dynamic liquid phase microextraction method (Castellote and Bengtsson 2011) using QP5000 GC-MS instrument (Shimadzu, Tokyo, Japan) equipped with fused-silica capillary column
(30 $\mathrm{m} \times 0.32 \mathrm{~mm} \times 0.25 \mu \mathrm{m})$ coated with bonded film of DB-1/5MS.

\section{Results and discussions}

As-prepared modified $\mathrm{ZnO}$ nanoparticles were characterized, and photocatalytic degradation using model dye solution under different light sources was studied. The photocatalytic activity of the modified $\mathrm{ZnO}$ for the degradation of chlorobenzene was also carried out in a laboratory-scale batch photoreactor under different light sources.

\section{Characterization of modified $\mathrm{ZnO}$ nanoparticles}

\section{Band-gap energy}

Band-gap energy (optical absorption properties) of pure $\mathrm{ZnO}$ and modified $\mathrm{ZnO}$ nanoparticles such as $\mathrm{Ag} / \mathrm{ZnO}, \mathrm{Cd} /$ $\mathrm{ZnO}$ and $\mathrm{Pb} / \mathrm{ZnO}$ was studied using $\mathrm{UV}-\mathrm{Vis}$ spectroscopic methods, and the results obtained can be seen in Fig. 1. It was noticed that the optical absorption edges of modified $\mathrm{ZnO}$ nanoparticles were considerably shifted toward the wavelength of visible range when compared to pure $\mathrm{ZnO}$. The equation $\mathrm{Eg}=1239.8 / \lambda$ was used to calculate the bandgap energy of all modified $\mathrm{ZnO}$ nanoparticles, where $\mathrm{Eg}$ is the band gap (eV) and $\lambda$ is the wavelength of the absorption edges in the UV-Vis spectrum (Zaleska-medynska 2006). Band-gap energy was observed to 3.15, 2.97, 2.91 and $2.81 \mathrm{eV}$ for pure $\mathrm{ZnO}, \mathrm{Ag} / \mathrm{ZnO}, \mathrm{Cd} / \mathrm{ZnO}$ and $\mathrm{Pb} / \mathrm{ZnO}$ nanoparticles, respectively. Highest band-gap energy shifting toward the visible range was observed in $\mathrm{Pb} / \mathrm{ZnO}$ than $\mathrm{Cd} /$ $\mathrm{ZnO}$ and $\mathrm{Pb} / \mathrm{ZnO}$. These results indicated that the presence of $\mathrm{Pb}, \mathrm{Cd}$ and $\mathrm{Ag}$ in $\mathrm{ZnO}$ system considerably reduces the

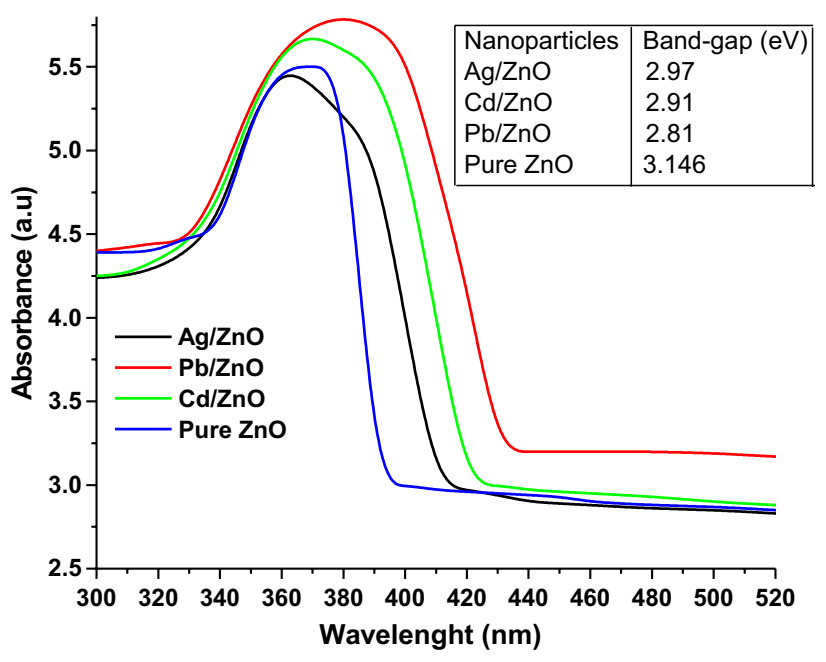

Fig. 1 Absorption edges and band-gap energies of modified $\mathrm{ZnO}$ nanoparticles in the UV-Vis spectrum

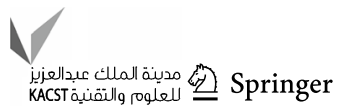


band-gap energy up to $10.7 \%, 7.5 \%$ and $5.6 \%$ toward visible range. It is worthy to note that absorption intensity was high for $\mathrm{Pb} / \mathrm{ZnO}$ compared to pure $\mathrm{ZnO}$ indicating the potential photocatalytic activity in the wavelength of visible range.

\section{Powder X-ray diffraction}

Crystalline structure and phase identification of modified $\mathrm{ZnO}$ (Ag-, Cd-, $\mathrm{Pb}$-doped $\mathrm{ZnO}$ ) nanoparticles were investigated using powder $\mathrm{X}$-ray diffraction technique with $\mathrm{CuK} \alpha$ $(\lambda=1.54056 \AA)$ as source with scanning range $10-80^{\circ}(2 \theta)$. The crystalline phases of modified $\mathrm{ZnO}$ nanoparticles were identified by comparing with JCPDS files (PCPDF WIN2.01). Average crystallite sizes were estimated from the Debye-Scherrer's equation $D=k \lambda / \beta \cos \theta$, where ' $D$ ' is the crystallite size; ' $\mathrm{k}$ ' is a constant ( $=0.9$ assuming that the particles are spherical); ' $\lambda$ ' is the wavelength of the X-rays; ' $\beta$ ' is the FWHM; ' $\theta$ ' is the diffraction angle in radians. Figure 2 shows the powder X-ray diffraction patterns of modified $\mathrm{ZnO}$ nanoparticles. XRD patterns of all modified $\mathrm{ZnO}$ nanoparticles showed sharp and high-intensity peaks when
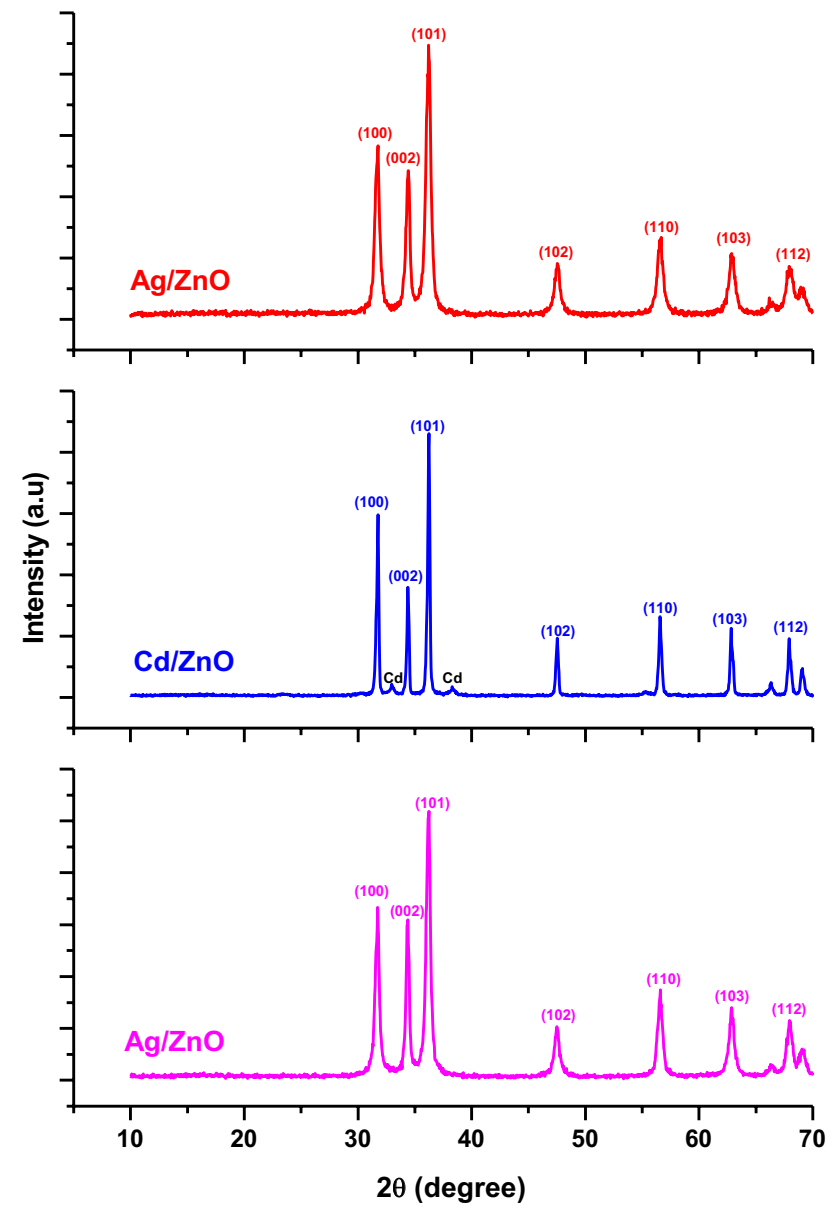

Fig. 2 Powder X-ray diffraction patterns of modified $\mathrm{ZnO}$ nanoparticles compared to pure $\mathrm{ZnO}$ (undoped) that may be attributed to the influence of dopents and solgel conditions under alkaline environment. The results obtained indicated highly crystalline phase of modified $\mathrm{ZnO}$ nanoparticles and XRD patterns were well matched with PCPDF: 050664. A strong peak (101) of $\mathrm{ZnO}$ was observed at $2 \theta=36.24^{\circ}$. Powder XRD patterns of modified $\mathrm{ZnO}$ nanoparticles showed all strong peaks corresponding to known diffraction maxima of $\mathrm{ZnO}$ $\left(2 \theta=31.7^{\circ}, 34.4^{\circ}, 36.2^{\circ}, 56.6^{\circ}\right.$ and $\left.62.8^{\circ}\right)$. The average crystalline sizes of modified $\mathrm{ZnO}$ nanoparticles were estimated using FWHM of the diffraction peak of XRD (Table 1).

\section{Scanning electron microscopy with energy-dispersive X-ray analysis}

Surface morphology and elemental analysis of modified $\mathrm{ZnO}$ nanoparticles were studied by scanning electron microscopy with energy-dispersive X-ray analysis. SEM images of Ag/ $\mathrm{ZnO}$ and $\mathrm{Cd} / \mathrm{ZnO}$ nanoparticles were observed to be irregular in shape and aggregated. Energy-dispersive X-ray analysis of $\mathrm{Ag} / \mathrm{ZnO}$ (Fig. 3) and $\mathrm{Cd} / \mathrm{ZnO}$ (Fig. 4) nanoparticles showed the presence of $\mathrm{Ag}$ and $\mathrm{Cd}$ elements in $\mathrm{ZnO}$ crystalline system, respectively. $\mathrm{Ag} / \mathrm{ZnO}$ and $\mathrm{Cd} / \mathrm{ZnO}$ nanoparticles were observed to be poly-scale in nature and agglomerated. When $\mathrm{Pb} / \mathrm{ZnO}$ nanoparticles were observed under scanning electron microscopy, nanorod shaped morphology with wellcrystalline structure and uniform-sized nanoparticles were observed (Fig. 5). The diameter of $\mathrm{Pb} / \mathrm{ZnO}$ nanorods was observed approximately 60 to $150 \mathrm{~nm}$ range, and it was also confirmed by XRD as well as DLS characterization results. Well-crystalline phase of modified $\mathrm{ZnO}$ particles was apparently stable from the perspective of chemical reactions that enhances the photocatalytic activities of $\mathrm{Pb} / \mathrm{ZnO}$.

\section{Fourier transformed infrared spectroscopy}

The functional groups and structural elucidations of modified $\mathrm{ZnO}$ nanoparticles were carried out using FTIR method. FTIR spectra of pure $\mathrm{ZnO}$ and modified $\mathrm{ZnO}$ nanoparticles can be seen in Fig. 6. The stretching bands corresponding to $\mathrm{ZnO}$ were obtained in the range of 500 to $400 \mathrm{~cm}^{-1}$ in all the FTIR spectra. The band at $1430 \mathrm{~cm}^{-1}$ corresponding to $\mathrm{C}=\mathrm{O}$ modes of vibration was observed in all FTIR spectra.

Table 1 Average crystalline size of modified $\mathrm{ZnO}$ nanoparticles

\begin{tabular}{lll}
\hline Modified ZnO nanoparticles & FWHM & $\begin{array}{l}\text { Average crys- } \\
\text { talline sizes } \\
(\mathrm{nm})\end{array}$ \\
\hline $\mathrm{Ag} / \mathrm{ZnO}$ & 0.045 & 191.8 \\
$\mathrm{Cd} / \mathrm{ZnO}$ & 0.031 & 287.7 \\
$\mathrm{~Pb} / \mathrm{ZnO}$ & 0.120 & 71.9 \\
\hline
\end{tabular}



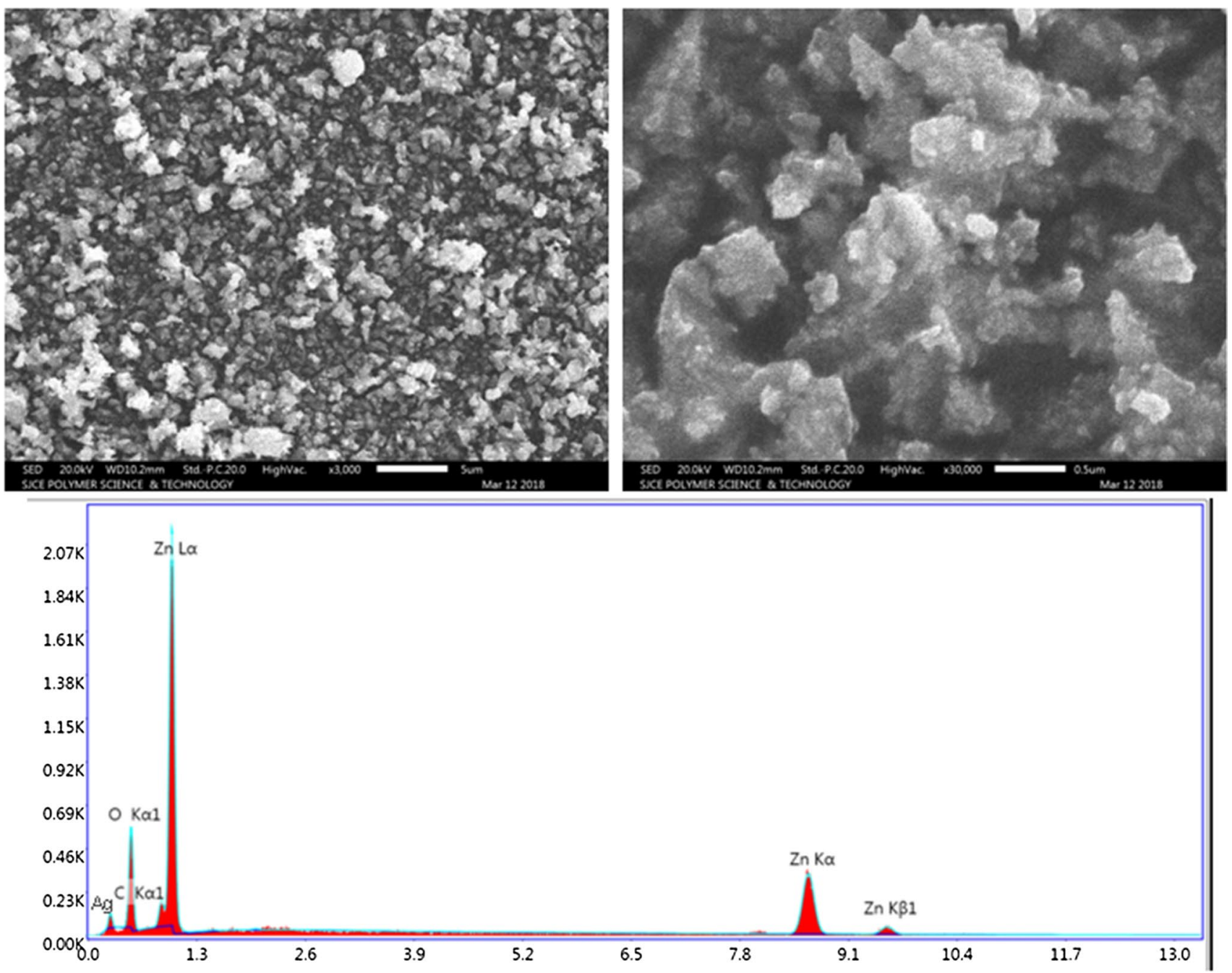

Fig. 3 Scanning electron microscopic images with energy-dispersive $\mathrm{X}$-ray analysis of $\mathrm{Ag} / \mathrm{ZnO}$ nanoparticles

The broad absorption peaks in the range of $3200-3600 \mathrm{~cm}^{-1}$ corresponding to $\mathrm{O}-\mathrm{H}$ group of $\mathrm{H}_{2} \mathrm{O}$ were observed in modified $\mathrm{ZnO}$ nanoparticles, and the existence of moistures on the surface of all modified $\mathrm{ZnO}$ nanoparticles was indicated . FTIR spectrum of $\mathrm{Ag} / \mathrm{ZnO}$ and $\mathrm{Cd} / \mathrm{ZnO}$ nanoparticles showed broad stretching vibration bands at $900-1150 \mathrm{~cm}^{-1}$ corresponding to $\mathrm{Zn}-\mathrm{O}-\mathrm{Ag}$ (Fig. 6) and $\mathrm{Cd}-\mathrm{O}-\mathrm{Zn}$ (Fig. 6), respectively, that indicates the interfacial region of $\mathrm{ZnO}$ and dopants. FTIR spectrum of $\mathrm{Pb} / \mathrm{ZnO}$ nanoparticles showed narrow stretching vibration bands at $900-1150 \mathrm{~cm}^{-1}$ corresponding to $\mathrm{Pb}-\mathrm{O}-\mathrm{Zn}$ and intensity of stretching bands corresponding to $\mathrm{Pb}-\mathrm{O}-\mathrm{Zn}$ comparatively high that indicates the presence of high $\mathrm{Pb}$ in $\mathrm{ZnO}$ crystalline structure.

\section{Dynamic light scattering}

Particle size of modified $\mathrm{ZnO}$ nanoparticles was determined by dynamic light scattering (DLS) particle size analyzer
(Malvern Zetasizer-Nano ZS) with $10 \mu \mathrm{L}$ minimum volume of sample suspension. The average sizes of $\mathrm{Ag} / \mathrm{ZnO}$, $\mathrm{Cd} / \mathrm{ZnO}$ and $\mathrm{Pb} / \mathrm{ZnO}$ nanoparticles were observed in the range of 210-350 nm (Fig. 7a), 150-360 nm (Fig. 7b) and 60-165 nm (Fig. 7c), respectively. The size of modified $\mathrm{ZnO}$ nanoparticles observed by DLS was also confirmed by XRD as well as SEM characterizations.

\section{BET surface area}

The specific surface area and porosity measurement of modified $\mathrm{ZnO}$ nanoparticles were analyzed by nitrogen adsorption in a Micromeritics TRIstar 3020 nitrogen absorption apparatus (USA). The corresponding nitrogen adsorption-desorption isotherms and the corresponding BET surface area of modified $\mathrm{ZnO}$ nanoparticles can be seen in Fig. 8. The surface morphology of $\mathrm{Pb} / \mathrm{ZnO}$ nanoparticles showed wide and relatively large volume of porosity (Fig. 8) when compared

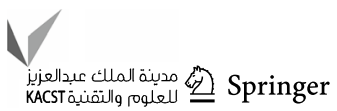



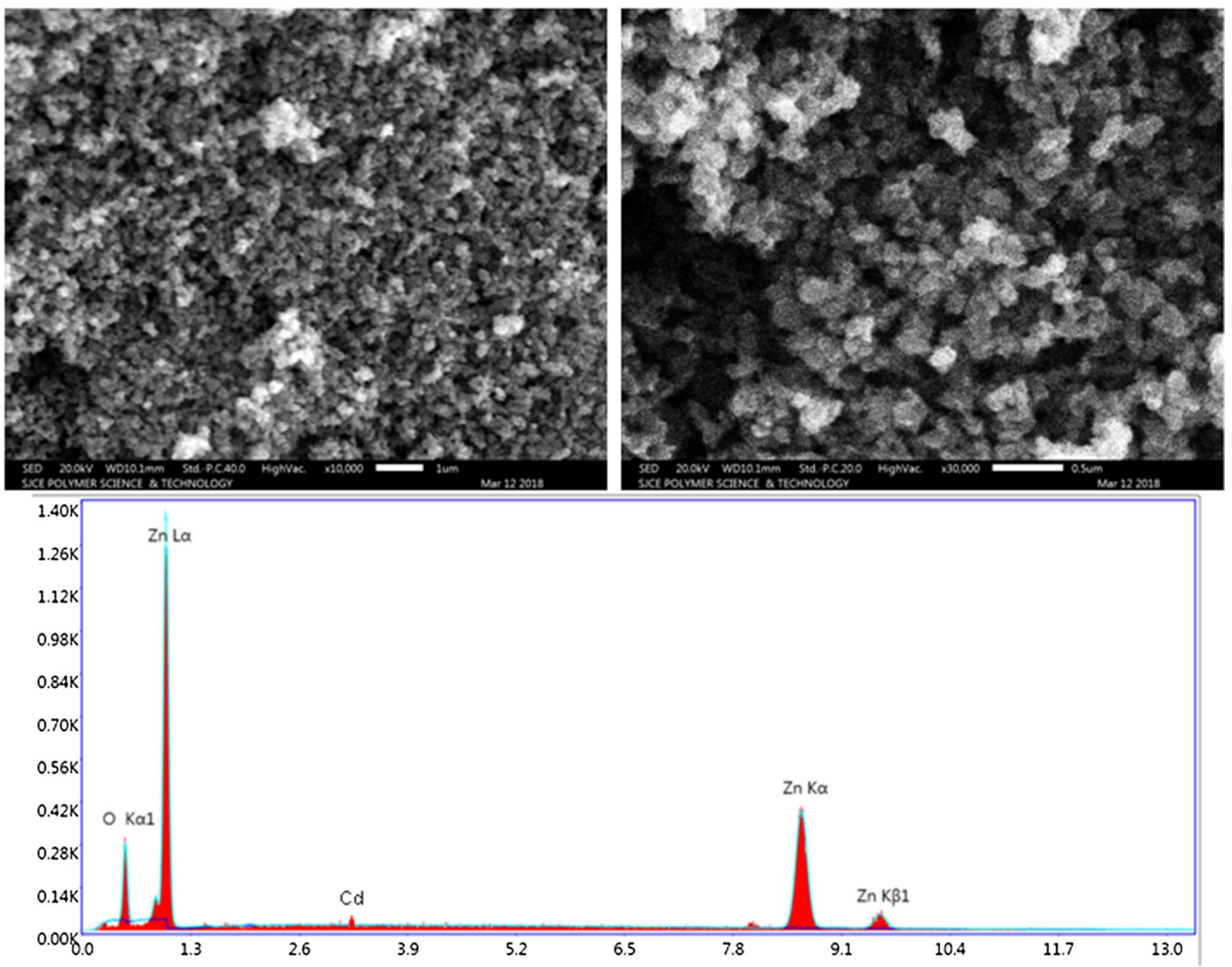

Fig. 4 Scanning electron microscopic images with energy-dispersive $\mathrm{X}$-ray analysis of $\mathrm{Cd} / \mathrm{ZnO}$ nanoparticles

to $\mathrm{Ag} / \mathrm{ZO}$ and $\mathrm{Cd} / \mathrm{ZnO}$ nanoparticles (Fig. 8a, b). The presence of high amount of nanoporous structures $(0.177176$ $\left.\mathrm{cm}^{3} \mathrm{~g}^{-1}\right)$ in $\mathrm{Pb} / \mathrm{ZnO}$ nanoparticles contributed to high pore volume, surface area and pore size. $\mathrm{Ag} / \mathrm{ZnO}$ and $\mathrm{Cd} / \mathrm{ZnO}$ showed rough surface morphology and clumping structure with relatively less surface area of 7.75 and $10.6 \mathrm{~m}^{2} / \mathrm{g}$, respectively, that might be attributed to accumulation of nanoparticles tightly without pore volume, and it was also confirmed by SEM characterization (Figs. 5 and 8c). $\mathrm{Pb} /$ $\mathrm{ZnO}$ nanoparticles showed considerable increased surface area up to $106.65 \mathrm{~m}^{2} / \mathrm{g}$, which could be attributed to wellcrystalline structure and squared-rod-shaped morphology of nanoparticles.

\section{Photocatalytic activity}

Photocatalytic activities of modified $\mathrm{ZnO}$ nanoparticles $(\mathrm{Ag} / \mathrm{ZnO}, \mathrm{Cd} / \mathrm{ZnO}$ and $\mathrm{Pb} / \mathrm{ZnO})$ were studied under different light sources using aqueous solution of methylene blue dye for 5-h irradiation. The results obtained clearly indicated potential photocatalytic activity of $\mathrm{Pb} / \mathrm{ZnO}$ nanoparticles under LED light sources than the $\mathrm{Ag} / \mathrm{ZnO}$ and $\mathrm{Cd} / \mathrm{ZnO}$ nanoparticles that may be attributed to the wellcrystalline and nanorod-shaped morphology observed in $\mathrm{Pb} / \mathrm{ZnO}$. All modified $\mathrm{ZnO}$ nanoparticles showed considerable photocatalytic degradation efficiency under LED light source followed by tungsten light, but pure $\mathrm{ZnO}$ nanoparticles showed potential photocatalytic activity under tungsten light (Fig. 9). The optical studies of modified $\mathrm{ZnO}$ nanoparticles also confirmed considerable shifting of band-gap energy toward the visible range that was the possible reason for highest photocatalytic activity under LED (1200 lx) and tungsten light (1600 lx) than UV light source $(1000 \mathrm{~lx})$. 

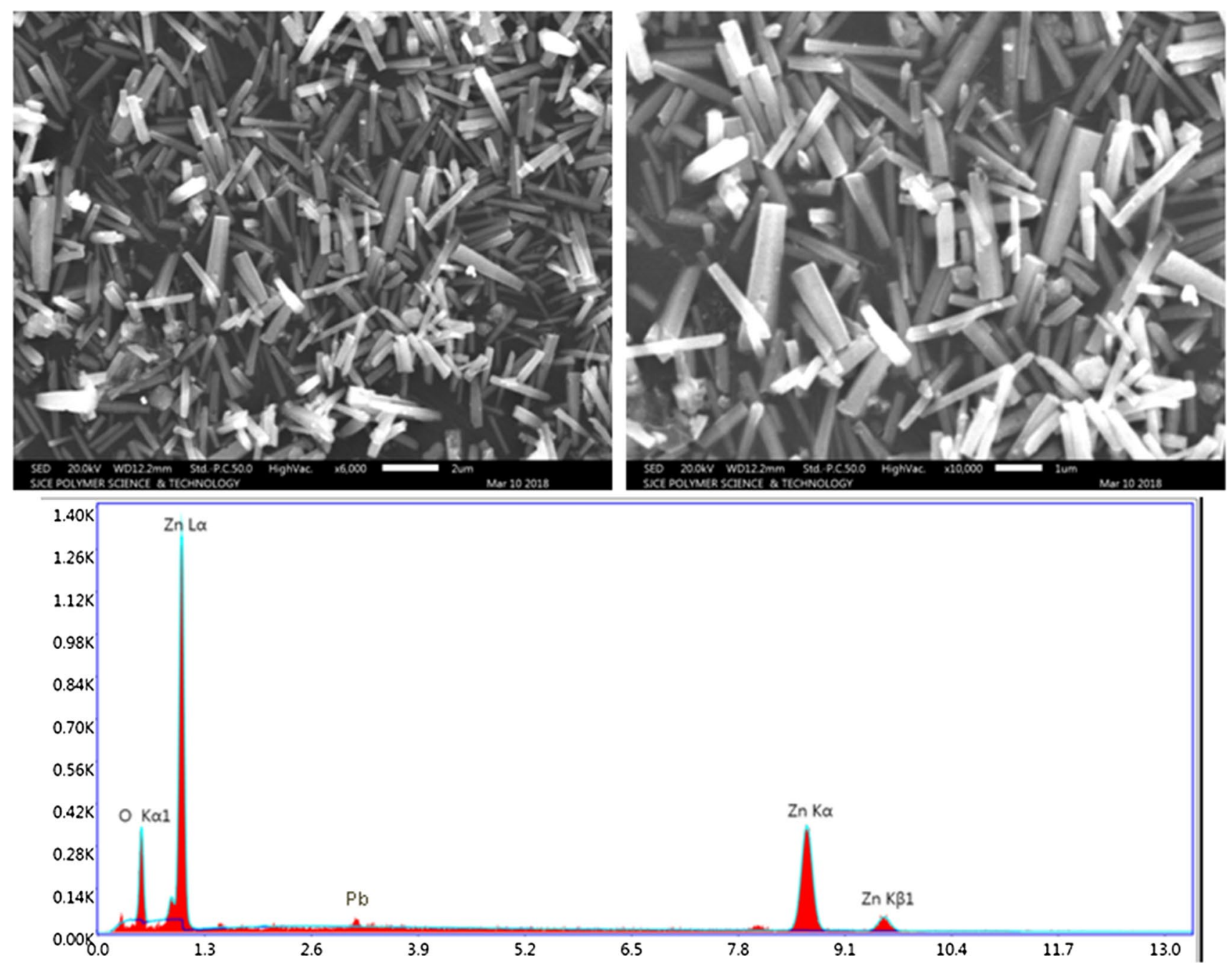

Fig. 5 Scanning electron microscopic images with energy-dispersive X-ray analysis of $\mathrm{Pb} / \mathrm{ZnO}$ nanoparticles

Fig. 6 FTIR spectra of a Pure $\mathrm{ZnO}$ nanoparticles; $\mathbf{b} \mathrm{Ag} /$ $\mathrm{ZnO}$ nanoparticles $\mathbf{c} \mathrm{Cd} / \mathrm{ZnO}$ nanoparticles; $\mathbf{d} \mathrm{Pb} / \mathrm{ZnO}$ nanoparticles
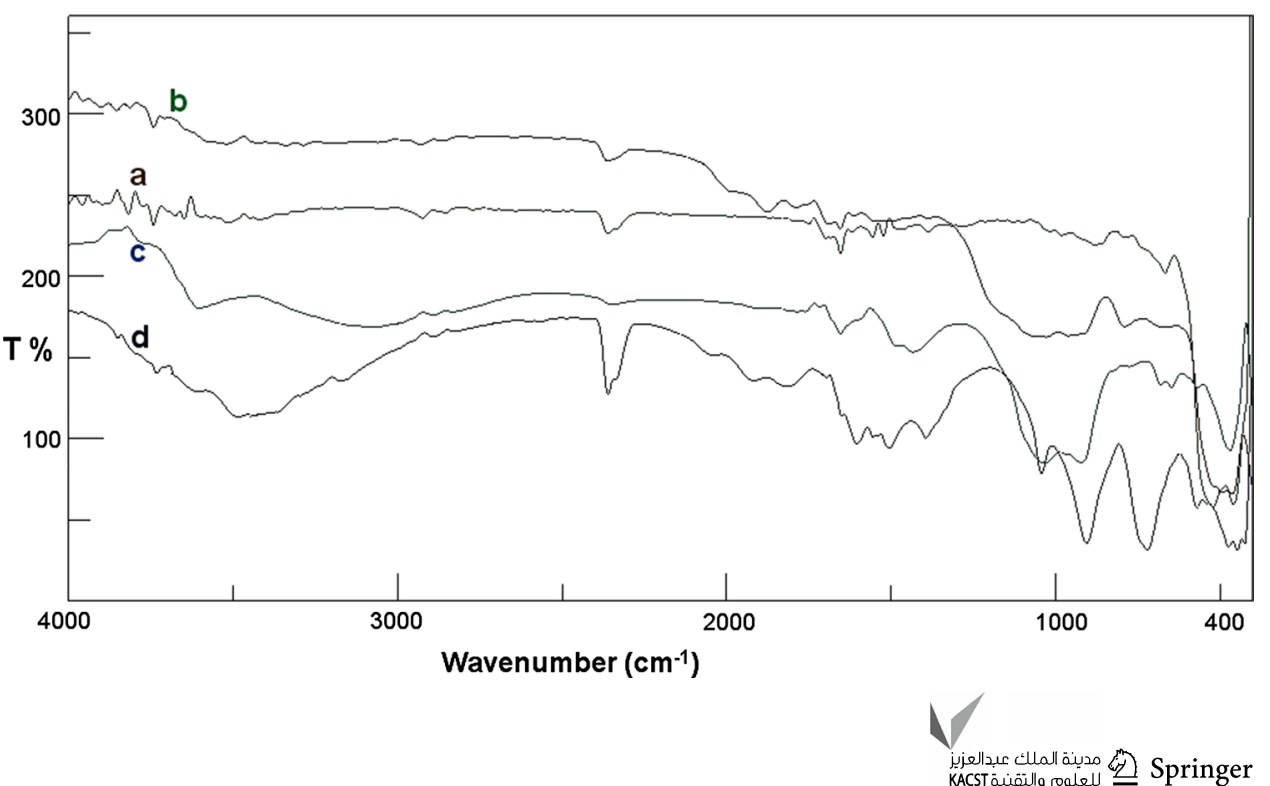

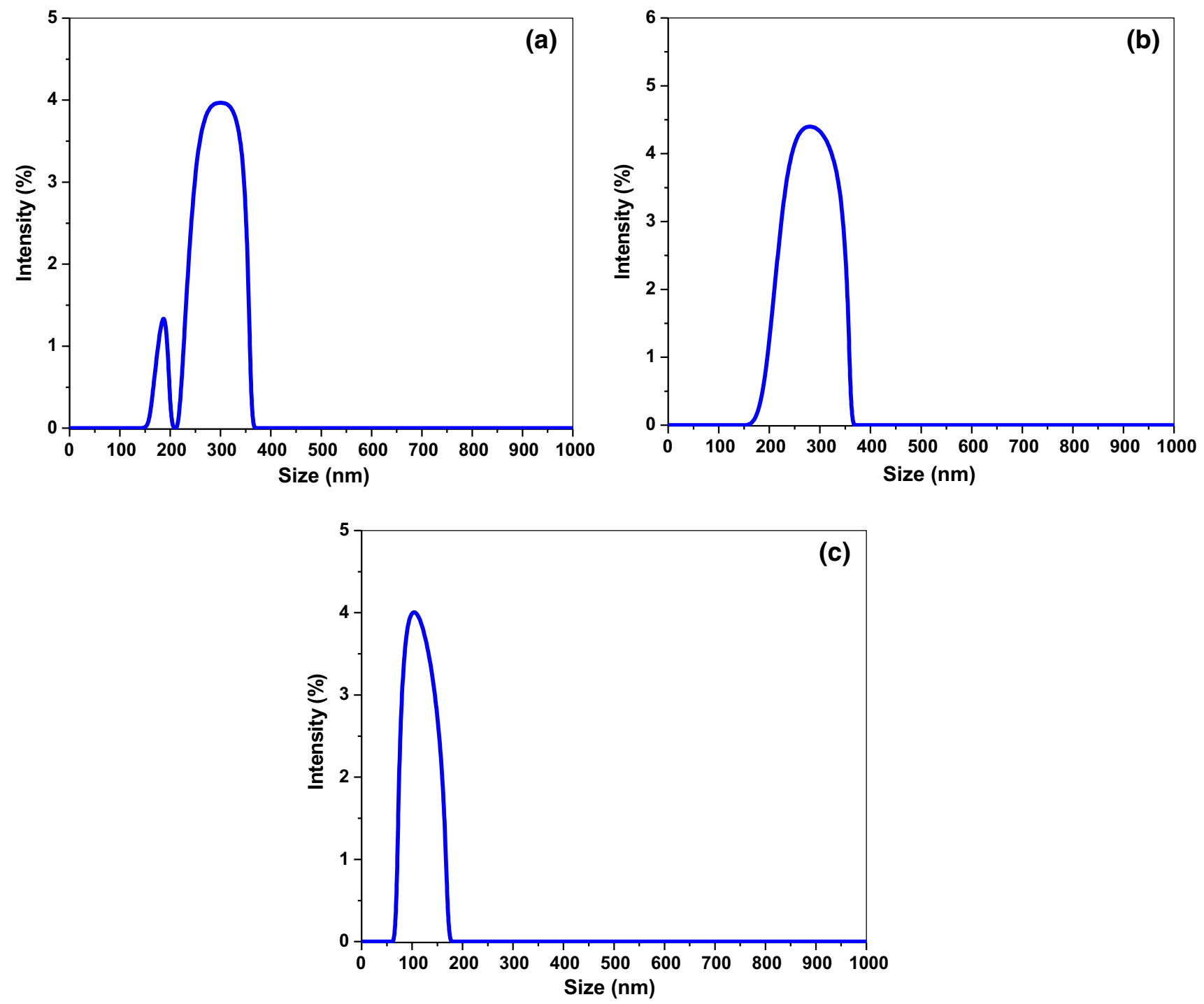

Fig. 7 Dynamic light scattering patterns of $\mathbf{a} \mathrm{Ag} / \mathrm{ZnO}$ nanoparticles $\mathbf{b} \mathrm{Cd} / \mathrm{ZnO}$ nanoparticles; $\mathbf{c} \mathrm{Pb} / \mathrm{ZnO}$ nanoparticles

\section{Degradation of chlorobenzene using modified ZnO nanoparticles}

The results obtained clearly indicated that photocatalytic degradation rate of chlorobenzene in an aqueous media using pure $\mathrm{ZnO}$ and modified $\mathrm{ZnO}(\mathrm{Ag} / \mathrm{ZnO}, \mathrm{Cd} / \mathrm{ZnO}$ and $\mathrm{Pb} / \mathrm{ZnO}$ ) nanoparticles found to be highest under tungsten (90\%) and LED (96\%, 91\% and 100\%) light sources, respectively. All modified $\mathrm{ZnO}$ nanoparticles showed potential degradation efficiency of chlorobenzene in an aqueous media under the visible range that was attributed to considerable band-gap energy shifting toward visible range due to incorporated dopants in $\mathrm{ZnO}$ systems. Among the modified $\mathrm{ZnO}$ nanoparticles, $\mathrm{Pb} / \mathrm{ZnO}$ nanoparticles were found to be efficient photocatalyst with rapid degradation rate of chlorobenzene under visible light source (Fig. 10c) and this also confirmed highest photocatalytic activity in $\mathrm{Pb} / \mathrm{ZnO}$ nanoparticles. Photocatalytic degradation efficiency of modified $\mathrm{ZnO}$ nanoparticles under different light sources can be seen in Fig. 10. Very interestingly, $\mathrm{Pb} / \mathrm{ZnO}$ nanoparticles showed rapid degradation of chlorobenzene in an aqueous media within short duration $(<120 \mathrm{~min}$ ) when compared to pure $\mathrm{ZnO}, \mathrm{Ag} / \mathrm{ZnO}$ and $\mathrm{Cd} / \mathrm{ZnO}$ nanoparticles.

\section{Photocatalytic degradation of chlorobenzene in a vertical continuous photoreactor}

Vertical continuous photoreactor model was designed using quartz tube $(7 \mathrm{~W} \times 26 \mathrm{~cm} \mathrm{~L})$ covered with borosil outer shield (10 W x $30 \mathrm{~cm} \mathrm{~L}$ ) provided with inlet and outlets. Vertical shaped LED light source was inserted from top of the quartz tube, and upper portion of photoreactor setup was 

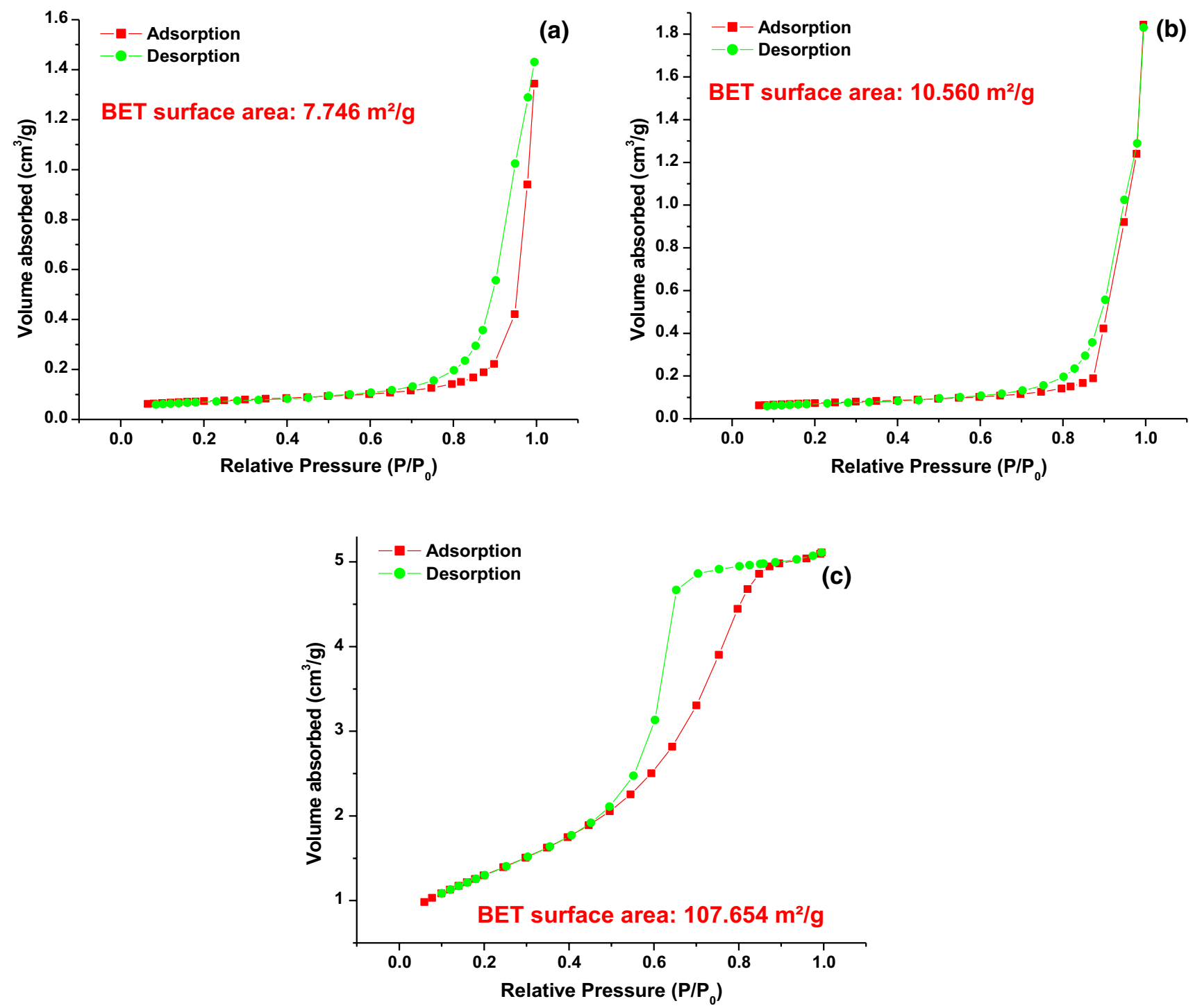

Fig. 8 BET surface area of $\mathbf{a} \mathrm{Ag} / \mathrm{ZnO}$ nanoparticles $\mathbf{b} \mathrm{Cd} / \mathrm{ZnO}$ nanoparticles; $\mathbf{c} \mathrm{Pb} / \mathrm{ZnO}$ nanoparticles

sealed by borosil glass led with air vent and electricity connections. The bottom of borosil outer shield was fixed with stirrer that connected to $16 \mathrm{~W}$ external motor for continuous stirring. The outer borosil shield was covered with aluminum sheet to enhance the illumination rate by light reflection, and the vertical continuous photoreactor setup designed can be seen in Fig. 11. The photodegradation efficiency of vertical continuous photoreactor was studied using $\mathrm{Pb} / \mathrm{ZnO}$ nanoparticles under LED light source by considering important factors such as flow rate, stirring and mode of catalyst load (slurry, floating and immobilize types). The aqueous solution of chlorobenzene $(2 \mathrm{~L}$ ) with $50 \mu \mathrm{g} / \mathrm{L}$ concentration was used for the studies, and external water pump $(50 \mathrm{~L} / \mathrm{h}$ capacity) was used to continuous circulation through the photoreactor. In slurry type of catalyst load, about $1 \mathrm{~g}$ of $\mathrm{Pb} / \mathrm{ZnO}$ nanoparticles was suspended in the aqueous solution and aqueous mixture was pumped continuously into photoreactor through inlet. In floating type, $\mathrm{Pb} / \mathrm{ZnO}$ nanoparticles were coated onto 2-mm Teflon beads using standard technique (Kumar et al. 2011) and directly suspended into reaction chamber of the photoreactor. In immobilized type, $\mathrm{Pb} / \mathrm{ZnO}$ nanoparticles were coated inner surface of outer shield by spreading technique using water proof binding agent (Kumar et al. 2011). All borosil tube ( $2 \mathrm{~cm}$ diameter) connections with reaction vessels were made leak proof with valves and connectors, and flow rate was controlled by pump speed and valves. Photocatalytic degradation efficiency of photoreactor designed using $\mathrm{Pb} / \mathrm{ZnO}$ nanoparticles was determined by analyzing initial and final concentration of chlorobenzene under GC-MS techniques.

The photodegradation results obtained using continuous-vertical photoreactor setup showed $100 \%$ degradation 


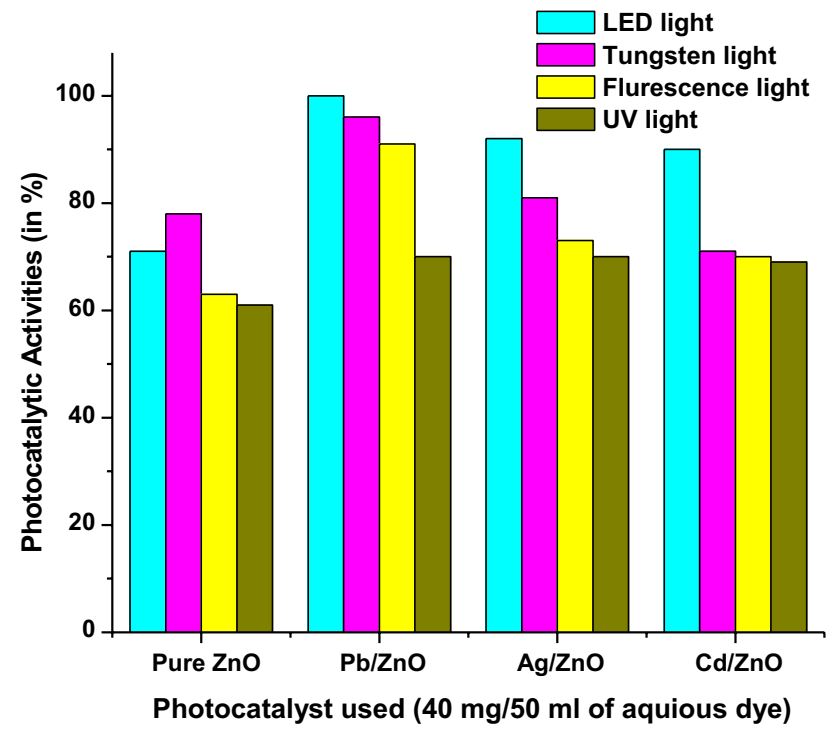

Fig. 9 Photocatalytic activities of modified $\mathrm{ZnO}$ nanoparticles under different light sources

rate within $2 \mathrm{~h}$ with flow rate of $10 \mathrm{~L} / \mathrm{h}$ under LED light (Fig. 12a). The results showed highest degradation efficiency in slurry type when compared to floating and immobilized type of catalyst load (Fig. 12b). Potential degradation efficiency in slurry type catalyst load may be attributed to complete and potential exposing of individual catalyst particles to photons and availability of active sites that apparently enhances the production rate of hydroxyl radicals in aqueous media. In floating and immobilized type of catalyst load, catalyst's surface that was adhere and bounded to the substrates (Teflon beads or borosil surface) would not be exposed to light sources or not available for photocatalytic activity in an aqueous media. Effect of stirring on photocatalytic degradation rate in the photoreactor was studied with different speeds and the results obtained indicated that moderate stirring mechanism significantly enhances the photocatalytic degradation efficiency in slurry type of catalyst load (Fig. 12c). It was also confirmed that degradation rate was also considerably influenced by flow rates (Fig. 12d) that might be attributed to the contact time of catalyst and chlorobenzene in the aqueous media. By considering the photoreactor type, it was confirmed that the irradiation time and flow rates depend on the types of photoreactor models and catalyst to be used. Query ID="Q1" Text="Please check and confirm the section headings are correctly identified."

\section{Conclusions}

The solgel preparation of modified $\mathrm{ZnO}$ nanoparticles was found to be effective in the degradation of chlorobenzene. The prepared $\mathrm{Ag} / \mathrm{ZnO}, \mathrm{Cd} / \mathrm{ZnO}$ and $\mathrm{Pb} / \mathrm{ZnO}$ have optimized band-gap energy of 2.97, 2.91 and 2.81, respectively. The crystalline size of the nanoparticle which was determined by using XRD is found to be 191.8, 287.7 and $71.9 \mathrm{~nm}$ for Ag/ $\mathrm{ZnO}, \mathrm{Cd} / \mathrm{ZnO}$ and $\mathrm{Pb} / \mathrm{ZnO}$, respectively. SEM image of $\mathrm{Ag} /$ $\mathrm{ZnO}, \mathrm{Cd} / \mathrm{ZnO}$ is found to be irregular in shape and aggregated, whereas for $\mathrm{Pb} / \mathrm{ZnO}$ is truncated nanorod-shaped morphology with well-spaced nanoparticles that appears to be well-crystalline phase. Average particle size and BET surface area of $\mathrm{Ag} / \mathrm{ZnO}, \mathrm{Cd} / \mathrm{ZnO}$ and $\mathrm{Pb} / \mathrm{ZnO}$ nanoparticles are found to be $210-350 \mathrm{~nm}$ and $7.456 \mathrm{~m}^{2} / \mathrm{g}, 150-360 \mathrm{~nm}$ and $10.56 \mathrm{~m}^{2} / \mathrm{g}$ and $60-165 \mathrm{~nm}$ and $107.654 \mathrm{~m}^{2} / \mathrm{g}$, respectively. Modified $\mathrm{ZnO}$ nanoparticles are effective in the degradation of chlorobenzene in the visible range spectrum. About $100 \%$ of chlorobenzene removal efficiency was obtained for $\mathrm{Pb} / \mathrm{ZnO}$ nanoparticle within a short duration $(<120 \mathrm{~min})$ under visible light source. To determine the efficiency of the photocatalyst, a vertical continuous reactor model was designed and demonstrated. Highest removal efficiency of chlorobenzene was obtained in a slurry-type reactor when compared to floating and immobilized type. The irradiation time and flow rate are the important factors to be considered for the effective degradation. 

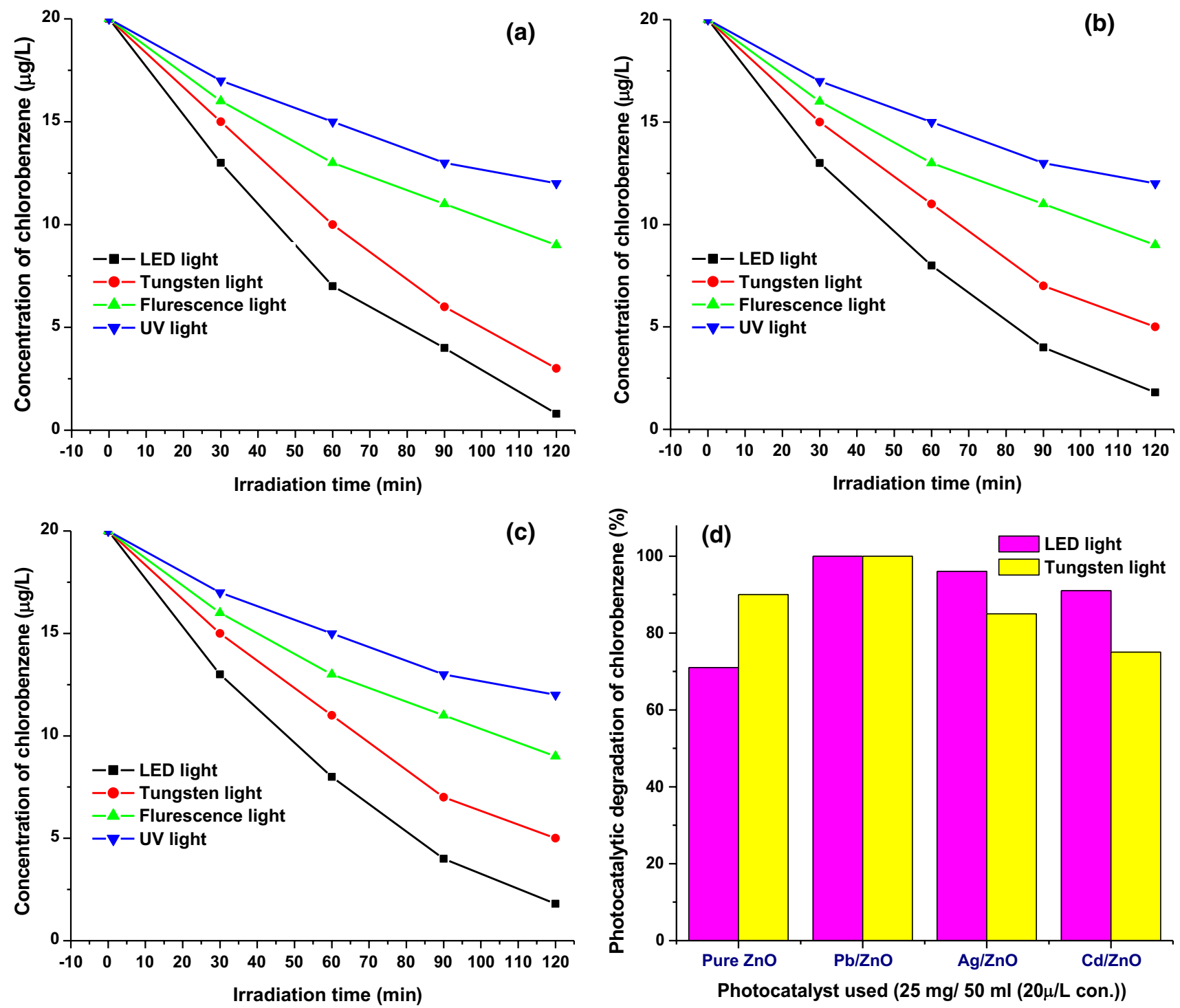

Fig. 10 Photocatalytic degradation of chlorobenzene using a $\mathrm{Ag} / \mathrm{ZnO} ; \mathbf{b} \mathrm{Cd} / \mathrm{ZnO} ; \mathbf{c} \mathrm{Pb} / \mathrm{ZnO}$ and d Degradation efficiency (in \%) of chlorobenzene using pure $\mathrm{ZnO}$ and modified $\mathrm{ZnO}$ nanoparticles under LED and tungsten light sources 
Fig. 11 Continuous photoreactor vertical model: (1) aqueous solution of chlorobenzene $(50 \mu \mathrm{g} / \mathrm{L})$ with $\mathrm{Fe}-\mathrm{Mn}-\mathrm{CeO}_{2} /$ $\mathrm{TiO}_{2}$ composite nanoparticles; (2) water pump with $50 \mathrm{~L} / \mathrm{h}$; (3) motor $320 \mathrm{~V}$; (4) flow controlling valve with glass pipe set $(2 \mathrm{~cm}$ diameter); (5) inlet of photoreactor; (6) borosil outer shield $(10 \mathrm{~cm} \mathrm{~W}$ x $30 \mathrm{~cm} \mathrm{L)}$; (7) quartz inner cover $(7 \mathrm{~cm} \mathrm{~W} \times 26 \mathrm{~cm} \mathrm{~L}) ;(8)$ light source (LED bulb, $16 \mathrm{~W}$ ); (9) stirrer with machine; (10) nanomembrane filter; (11) upper lid with light intensity controller and electric connections; (12) outlet of photoreactor; (13) gas outlet of photoreactor

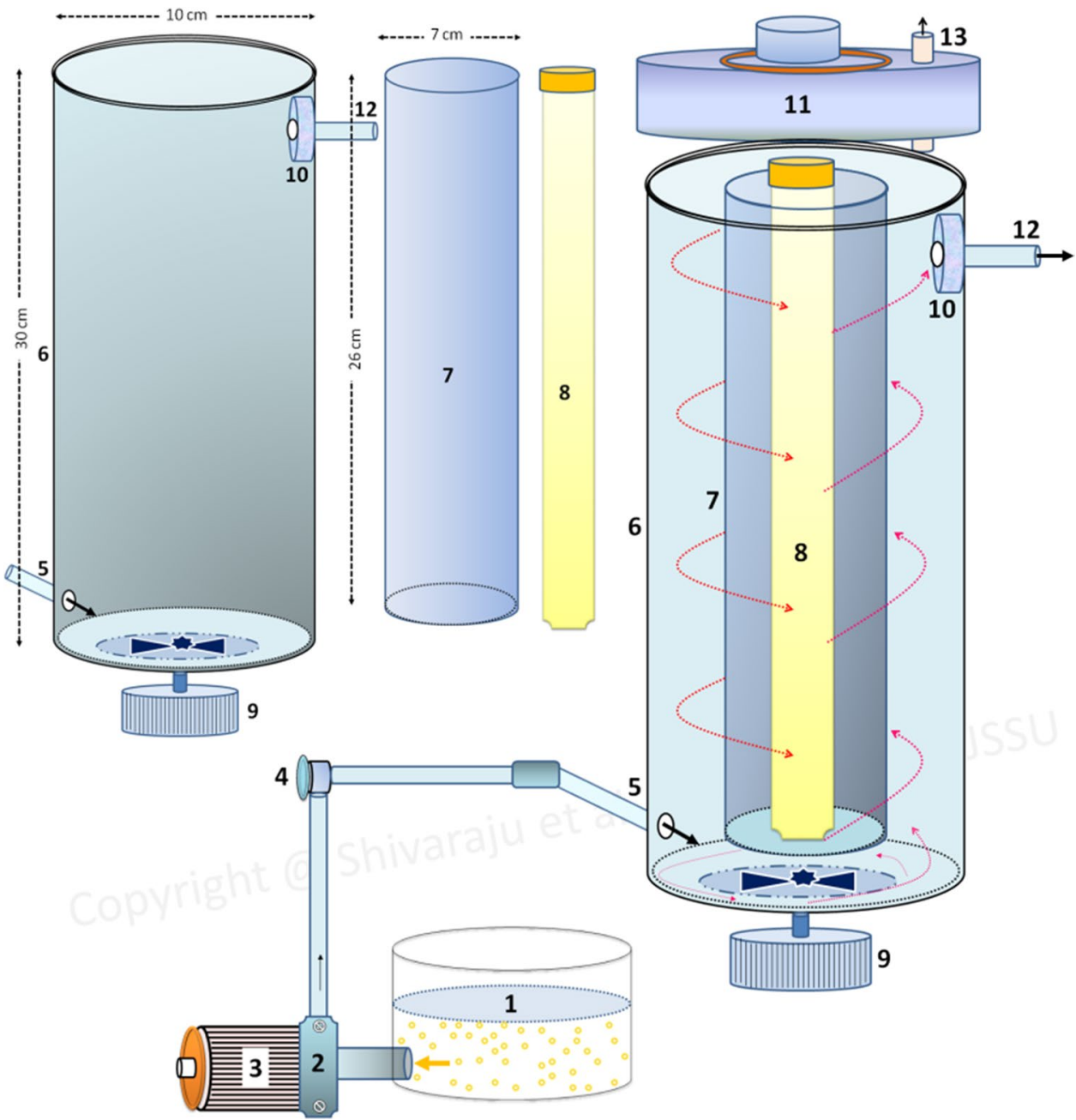



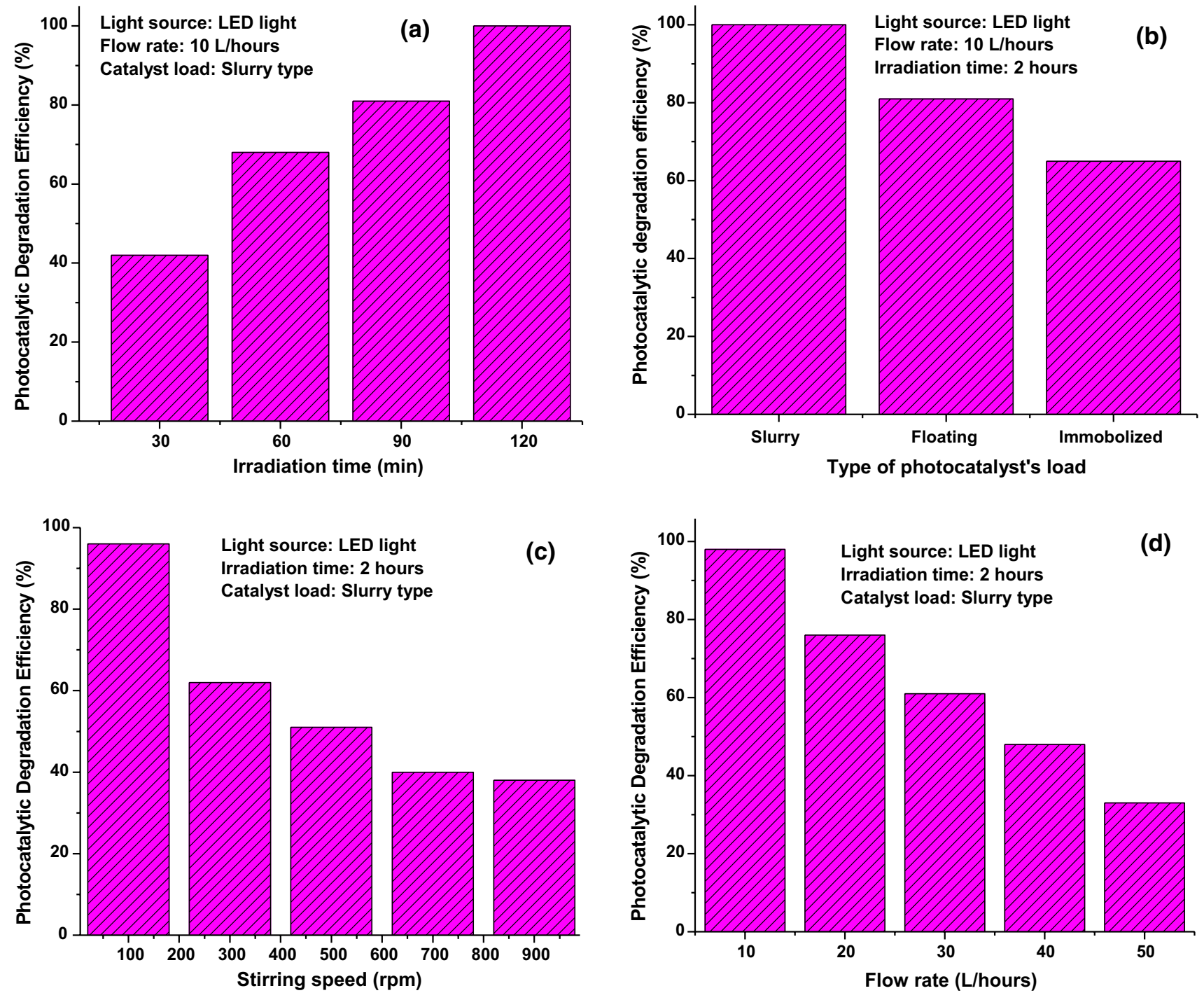

Fig. 12 Photocatalytic degradation of chlorobenzene using continuous (vertical) photoreactor setup $\mathbf{a}$ effect of irradiation time; $\mathbf{b}$ effect of photocatalyst's loading type; $\mathbf{c}$ effect of irradiation time; $\mathbf{d}$ effect of flow rate

Acknowledgements The authors would like to thank JSS Academy of Higher Education and Research (JSS AHER), Mysuru, India, for providing financial assistance to conduct the research work. University of Mysore and JSS Science and Technology University, Mysuru, acknowledged for instrumentation facilities. The authors thank Dr. Anil Kumar KM, Pallavi S, Midhun G researcher fellows from Department of Water and Health, JSS AHER for providing necessary assistance to complete the research work.

Funding The authors declare that they have no funding supported for this research.

\section{Compliance with ethical standards}

Conflict of interest The authors declare that they have no conflict of interest.
Open Access This article is licensed under a Creative Commons Attribution 4.0 International License, which permits use, sharing, adaptation, distribution and reproduction in any medium or format, as long as you give appropriate credit to the original author(s) and the source, provide a link to the Creative Commons licence, and indicate if changes were made. The images or other third party material in this article are included in the article's Creative Commons licence, unless indicated otherwise in a credit line to the material. If material is not included in the article's Creative Commons licence and your intended use is not permitted by statutory regulation or exceeds the permitted use, you will need to obtain permission directly from the copyright holder. To view a copy of this licence, visit http://creativecommons.org/licenses/by/4.0/.

\section{References}

Ameta R, Benjamin S, Ameta A, Ameta SC (2012) Photocatalytic degradation of organic pollutants: a review. Mater Sci Forum 
734:247-272. https://doi.org/10.4028/www.scientific.net/ MSF.734.247

Anandan S, Ikuma Y, Niwa K (2010) An overview of semi-conductor photocatalysis: modification of $\mathrm{TiO}_{2}$ nanomaterials. Solid State Phenom 162:239-260. https://doi.org/10.4028/www.scientific.net/ SSP.162.239

Aneesh PM, Vanaja KAMKJ (2007) Synthesis of ZnO nanoparticles by hydrothermal method. Nanophotonic Mater IV. https://doi. org/10.1117/12.730364

Bacaksiz E, Parlak M, Tomakin M, Özçelik A, Karakız M, Altunbaş M (2008) The effect of zinc nitrate, zinc acetate and zinc chloride precursors on investigation of structural and optical properties of $\mathrm{ZnO}$ thin films. J Alloys Compd 466:447-450. https://doi. org/10.1016/j.jallcom.2007.11.061

Berenjian A, Chan N, Malmiri HJ (2012) Volatile organic compounds removal methods: a review. Am J Biochem Biotechnol 8:220-229. https://doi.org/10.3844/ajbbsp.2012.220.229

Brintha SR, Ajitha M (2015) Synthesis and characterization of $\mathrm{ZnO}$ nanoparticles via aqueous solution, sol-gel and hydrothermal methods. IOSR J Appl Chem 8:66-72. https://doi. org/10.9790/5736-081116672

Castellote M, Bengtsson N (2011) Applications of titanium dioxide photocatalysis to construction materials. Springer Int Publ. https ://doi.org/10.1007/978-94-007-1297-3

Chen X, Mao SS (2007) Titanium dioxide nanomaterials: synthesis, properties, modifications and applications. Chem Rev 107:2891-2959. https://doi.org/10.1021/cr0500535

Chen YF, Lee CY, Yeng MY, Chiu HT (2003) The effect of calcination temperature on the crystallinity of $\mathrm{TiO}_{2}$ nanopowders. J Cryst Growth 247:363-370. https://doi.org/10.1016/S0022 -0248(02)01938-3

Crutzen PJ, Lawrence MG, Pöschl U (1999) On the background photochemistry of tropospheric ozone. Tellus. Ser A Dyn Meteorol Oceanogr 51:123-146. https://doi.org/10.1034/j.1600-0870.1999. t01-1-00010.x

Das D, Gaur V, Verma N (2004) Removal of volatile organic compound by activated carbon fiber. Carbon N Y 42:2949-2962. https://doi. org/10.1016/j.carbon.2004.07.008

Djurišić AB, Leung YH, Ching Ng AM (2014) Strategies for improving the efficiency of semiconductor metal oxide photocatalysis. Mater Horizons 1:400. https://doi.org/10.1039/c4mh00031e

Eltouny N (2009) Reduction of anthropogenic volatile and semi-volatile organic compounds by nanomaterials and photolysis. Molecules 21:56

Font X, Artola A, Sánchez A (2011) Detection, composition and treatment of volatile organic compounds from waste treatment plants. Sensors 11:4043-4059. https://doi.org/10.3390/s110404043

Goldstein Allen H (2007) Known and Unexplored organic constituents in the earth's atmosphere. Environ Sci Technol 41:1514-1521

Guo H, Kwok NH, Cheng HR, Lee SC, Hung WT, Li YS (2009) Formaldehyde and volatile organic compounds in Hong Kong homes: concentrations and impact factors. Indoor Air 19:206-217. https ://doi.org/10.1111/j.1600-0668.2008.00580.x

Hasnidawani JN, Azlina HN, Norita H, Bonnia NN, Ratim S, Ali ES (2016) Synthesis of $\mathrm{ZnO}$ nanostructures using sol-gel method. Procedia Chem 19:211-216. https://doi.org/10.1016/j.proch e.2016.03.095

Huang Y, Ho SSH, Niu R, Xu L, Lu Y, Cao J, Lee S (2016) Removal of indoor volatile organic compounds via photocatalytic oxidation: a short review and prospect. Molecules. https://doi.org/10.3390/ molecules 21010056

Khan FI, Ghoshal A (2000) Removal of volatile organic compounds from polluted air. J Loss Preven Process Ind 527:545. https://doi. org/10.1016/S0950-4230(00)00007-3

Khan R, Khan M, Hameedullah AH, Ansari A, Lohani M, Khan R, Ahmad I, Husain FM, Khan W, Alam M (2014) Flower-shaped
$\mathrm{ZnO}$ nanoparticles synthesized by a novel approach at near-room temperatures with antibacterial and antifungal properties. Int J Nanomed 9:853. https://doi.org/10.2147/IJN.S47351

Kim H, Choi W (2007) Effects of surface fluorination of $\mathrm{TiO}_{2}$ on photocatalytic oxidation of gaseous acetaldehyde. Appl Catal B Environ 69:127-132. https://doi.org/10.1016/J.APCATB.2006.06.011

Kumar D, Abhang RM, Taralkar SV (2011) Design of photocatalytic reactor for degradation of phenol in wastewater. Int J Chem Eng Appl 2:3144-3148. https://doi.org/10.1016/S0045-6535(01)00327-7

Lin L, Chai Y, Zhao B, Wei W, He D, He B, Tang Q (2013) Photocatalytic oxidation for degradation of VOCs. Open J Inorg Chem 03:14-25. https://doi.org/10.4236/ojic.2013.31003

Malekshahi Byranvand M, Kharat AN, Fatholahi L, Beiranvand ZM (2013) A review on synthesis of nano- $\mathrm{TiO}_{2}$ via different methods. JNS 3:1-9

Malik A, Hameed S, Siddiqui MJ, Haque MM, Muneer M (2013) Influence of ce doping on the electrical and optical properties of $\mathrm{TiO}_{2}$ and its photocatalytic activity for the degradation of remazol brilliant blue R. Int J Photoenergy. https://doi. org/10.1155/2013/768348

Meena RK, Chouhan N (2015) ZnO nanoparticles synthesized by a novel approach at room temperature and antibacterial activity. Science 56:68-72

Midhun G, Shivaraju HP, Anil Kumar KM (2017) Effects of cationic ligands addition in hydrous titanium oxide on fluoride removal efficiency in aqueous medium. Int $\mathbf{J}$ Environ Health Technol $1(1): 1-7$

Nakata K, Fujishima A (2012) $\mathrm{TiO}_{2}$ photocatalysis: design and applications. J Photochem Photobiol C Photochem Rev 13:169-189. https ://doi.org/10.1016/j.jphotochemrev.2012.06.001

Prabhat Kumar T, Anil Kumar M, Chandrajit B (2011) Biofiltration of volatile organic compounds (VOCs) - an overview. Res J Chem Sci Res J Chem Sci 1:2231-2606

Prieto O, Fermoso J, Irusta R (2007) Photocatalytic degradation of toluene in air using a fluidized bed photoreactor. Int J Photoenergy. https://doi.org/10.1155/2007/32859

Rajput N (2015) Methods of preparation of nanoparticles-a review. Int J Adv Eng Technol 7:1806-1811

Ramesh S (2013) Sol-gel synthesis and characterization nanoparticles $\mathrm{Ag}_{3}(2+\mathrm{x})$ AlxTi4-xO11 $+\delta(0.0 \leq \mathrm{x} \leq 1.0)$. J Nanosci 13:9

Rangkooy H, Rezaee A, Khavanin A, Jafari AJ, Khoopaie A (2012) A study on photocatalytic removal of formaldehyde from air using $\mathrm{ZnO}$ nanoparticles immobilized on bone char background and objectives: formaldehyde is one of the toxic polluted air. Photocatalysis 7:1-4

Reddy VL, Kim PKH, Kim YH (2011) A review of photocatalytic treatment for various air pollutants. Asian J Atmos Environ 5:181188. https://doi.org/10.5572/ajae.2011.5.3.181

Rehman S, Ullah R, Butt AM, Gohar ND (2009) Strategies of making $\mathrm{TiO}_{2}$ and $\mathrm{ZnO}$ visible light active. J Hazard Mater 170:560-569. https://doi.org/10.1016/j.jhazmat.2009.05.064

Said Ismail OM, Hameed RSA (2013) Environmental effects of volatile organic compounds on ozone layer. Pelagia. Res Libr Adv Appl Sci Res 4:264-268

Salahuddin NA, El-kemary M, Ibrahim EM (2015) Synthesis and characterization of $\mathrm{ZnO}$ nanotubes by hydrothermal method. Int J Sci Res Publ 5:3-6

Sharma A, Karn RK, Pandiyan SK (2014) Synthesis of $\mathrm{TiO}_{2}$ nanoparticles by sol-gel method and their characterization. J Basic Appl Eng Res 1:2350-2377

Shivaraju HP (2012) Hydrothermal synthesis of $\mathrm{ZnO}$ nanostructures onto calcium alumino-silicate ceramic supports. J Nano Sci Nano Technol 6(1):5-8

Shivaraju HP, Byrappa K (2012) The role of hydrothermally prepared supported photocatalytic composite in organic micro-pollutants removal from the water. J Environ Sci Eng 54(3):353-364 
Shivaraju HP, Chandrashekar CK (2012) Photocatalytic removal of organic pollutants in silk industrial effluents by $\mathrm{ZnO}$ deposited CASB supported composite. Int J Res Chem Environ 2(2):26-31

Shivaraju HP, Muzakkira N, Shahmoradi B (2016) Photocatalytic treatment of oil and grease spills in wastewater using coated $\mathrm{N}$-doped $\mathrm{TiO}_{2}$ polyscales under sunlight as an alternative driving energy. Int J Environ Sci Technol 13(9):2293-2302

Tanizaki T, Murakami Y, Hanada Y, Ishikawa S, Suzuki M, Shinohara $\mathrm{R}$ (2007) Titanium dioxide $\left(\mathrm{TiO}_{2}\right)$-assisted photocatalytic degradation of volatile organic compounds at ppb level. Carbon N Y 53:514-519

Tseng TK, Lin YS, Chen YJ, Chu H (2010) A review of photocatalysts prepared by sol-gel method for VOCs removal. Int J Mol Sci 11:2336-2361. https://doi.org/10.3390/ijms11062336

Wong CL, Tan YN, Mohamed AR (2011) A review on the formation of titania nanotube photocatalysts by hydrothermal treatment. J Environ Manag 92:1669-1680. https://doi.org/10.1016/J.JENVM AN.2011.03.006
Zaleska-medynska A (2006) UV/VIS light enhanced photocatalysis for water treatment and protection. Springer Int Publ. https://doi. org/10.1007/978-1-4020-4728-2

Zou L, Hu E, Luo Y, Atkinson S (2004) Experimental study of the degradation of volatile organic compounds by photocatalytic oxidation using $\mathrm{TiO}_{2}$ pellets. In: Brebbia (ed) Air pollution XII C. WIT Press

Zou L, Luo Y, Hooper M, Hu E (2006) Removal of VOCs by photocatalysis process using adsorption enhanced $\mathrm{TiO}_{2}-\mathrm{SiO}_{2}$ catalyst. Chem Eng Process Process Intens 45:959-964. https://doi. org/10.1016/j.cep.2006.01.014

Publisher's Note Springer Nature remains neutral with regard to jurisdictional claims in published maps and institutional affiliations. 